\title{
INFLUÊNCIA DO TAMANHO DA PARTÍCULA NA FLOTAÇÃO COM AMINA
}

\author{
J. L. O. Barbosa ${ }^{1}$ e C. A. M. Baltar ${ }^{2}$ \\ ${ }^{1}$ Universidade Federal de Pernambuco - Grupo de Tecnologia Mineral \\ joao_lucasdeminas@hotmail.com - camb@ufpe.br
}

Artigo submetido em outubro/2012 e aceito em novembro/2012

\section{RESUMO}

A flotação de finos é um problema conhecido, especialmente, quando se usa um coletor que se adsorve por atração eletrostática. Nesse trabalho estudou-se a influência da granulometria na flotação catiônica do quartzo. Usou-se uma dodecilamina (DDA) e o metilisobutilcarbinol (MIBC) como coletor e espumante, respectivamente. Os testes foram realizados em célula mecânica convencional e os resultados foram avaliados em termos da percentagem em peso obtida no flotado. Os resultados evidenciaram a maior dificuldade de flotação das partículas finas. A amostra com tamanho médio de $42 \mu \mathrm{m}$ flotou praticamente toda com apenas dois minutos de flotação, enquanto a amostra mais fina $\left(d_{50}=17 \mu_{m}\right)$ teve uma recuperação de apenas $25 \%$ no mesmo período. A dificuldade é atribuída a uma menor densidade de adsorção do coletor nas partículas mais finas devido à maior área superficial. No entanto, a recuperação aumentou para aproximadamente $77 \%$ com o prolongamento do tempo de flotação e chegou a $95 \%$ com o aumento da concentração do coletor.

PALAVRAS-CHAVE: flotação de finos; coletor catiônico; amina, flotação de quartzo; recobrimento superficial.

\section{THE INFLUENCE OF PARTICLE SIZE ON THE FLOTATION WITH AMINE}

\begin{abstract}
The flotation of fine particles is a notorious problem, mainly when is used a collector that adsorbs by electrostatic attraction. In this research it was studied the influence of the particle size on cationic flotation of quartz. It was used a dodecylamine (DDA) and methylisobutylcarbinol (MIBC) as collector and frother, respectively. The tests were carried out in a mechanical conventional cell and the results were evaluated based on the weight percentage of the floated sample. The results proved the greater difficulty of the fine particles
\end{abstract}

to float. The flotation of the sample with medium size of $42 \mu_{m}$ was very fast, practically all sample was floated in two minutes. Whereas the finest sample $\left(d_{50}=17 \mu_{\mathrm{m}}\right)$ recovery yielded only $25 \%$ at same flotation period. The difficulty is attributed to a lower density of adsorption of the collector in the fines particles due their greater surface area. Nevertheless, the recovery increased to near $77 \%$ with the prolongation of the flotation time and attained $95 \%$ when there was an increase of the collector concentration.

KEY-WORDS: fines flotation, cationic collector, amine, quartz flotation, superficial coating. 


\section{INFLUÊNCIA DO TAMANHO DA PARTÍCULA NA FLOTAÇÃO COM AMINA}

\section{INTRODUÇÃO}

A flotação de quartzo tradicionalmente é feita com o uso de alguma das variedades de amina. A amina primária é obtida a partir da amônia pela substituição de um átomo de hidrogênio por um grupo orgânico $\left(\mathrm{RNH}_{2}\right)$. As aminas usadas em flotação, geralmente, possuem uma cadeia orgânica com 8 a 10 carbonos. Esses reagentes ionizam por protonação de acordo com a reação: $\mathrm{RNH}_{2}+\mathrm{H}_{2} \mathrm{O} \rightleftharpoons \mathrm{RNH}_{3}^{+}+\mathrm{OH}^{-}$.

A partir da amina primária, outros coletores catiônicos foram desenvolvidos e têm sido frequentemente utilizados, a exemplo da eteramina na flotação reversa de minério de ferro (PEARSE, 2005; ARAÚJO et al., 2005). A molécula da eteramina caracteriza-se pela presença de um segundo grupo polar $\left(\mathrm{O}-\mathrm{CH}_{2}\right)_{3}$, que confere ao reagente melhor solubilidade (BALTAR, 2010).

Esse tipo de coletor adsorve-se fisicamente à superfície mineral por meio de atração eletrostática. Isso significa que um pré-requisito para que a adsorção seja viabilizada é que a superfície apresente um excesso de carga negativa. $\mathrm{O}$ quartzo tem ponto isoelétrico em $\mathrm{pH}$ entre 2,0 e 4,0 (HUNTER, 1988) o que garante uma adsorção eficiente em uma ampla faixa de $\mathrm{pH}$.

A quantidade de moléculas adsorvidas aumenta proporcionalmente à quantidade de sítios disponíveis na superfície mineral. $\mathrm{O}$ excesso de carga negativa aumenta com o $\mathrm{pH}$. A densidade de adsorção é refletida na hidrofobicidade adquirida e, consequentemente, na velocidade de flotação.

Uma adsorção física é caracterizada por uma baixa energia de adsorção e pouca seletividade já que, a princípio, qualquer superfície com carga contrária é atraente para a molécula do coletor. A baixa energia envolvida na interação permite, por exemplo, a reciclagem do reagente (BALTAR et al., 2002).

Por sua vez, devido ao seu caráter pouco seletivo, esse tipo de coletor deve ser evitado na flotação de minério com quantidade considerável de finos. Devido à maior área superficial e maior energia livre de superfície dessas partículas, a amina é consumida preferencialmente pelos finos, resultando em uma redução na recuperação geral do processo (BALTAR e VILLAS BOAS, 1980). A ineficiência das aminas para a flotação de finos é conhecida. No entanto, não há uma definição precisa do tamanho da partícula mínimo para uma flotação eficiente.

O objetivo do trabalho foi verificar a influência do tamanho da partícula da velocidade de flotação catiônica de quartzo. 


\section{EXPERIMENTAL}

\section{Material}

Usou-se uma amostra de quartzo proveniente do Estado da Paraíba de onde foram coletadas em blocos que somaram cerca de $33 \mathrm{Kg}$.

\section{Reagentes}

Utilizou-se uma dodecilamina (DDA) comercializada pela SIGMA-ALDRICH como coletor e o metilisobutilcarbinol (MIBC) comercial fornecido pela FLOMIM. A regulagem do $\mathrm{pH}$ foi feita com hidróxido de sódio $(\mathrm{NaOH})$ ou $\mathrm{H}_{2} \mathrm{SO}_{4}$ (ácido sulfúrico) fabricados pela MERCK.

\section{Equipamentos}

A fragmentação foi feita com o uso de britadores (de mandíbula e de rolos) e de um moinho de bolas.

Na preparação da amostra usou-se um peneirador vibratório da marca VIA TEST e um Separador Magnético de rolo induzido da EQUIMAG.

Os testes de flotação foram feitos em Célula Mecânica de Flotação, sub-A, DENVER, com cubas de 3 litros.

Para a determinação do potencial zeta foi usada a técnica eletroacústica com o Sistema ESA-9800 da MATEC.

A distribuição de tamanhos das partículas e a área superficial foram determinadas com o Granulômetro a laser Mastersizer 2000 da MALVERN.

\section{Metodologia}

A amostra foi inicialmente fragmentada a uma granulometria abaixo de 200 malhas. Em seguida, foi separada em quatro faixas granulométricas: 200×270\#, 270×325\#, 325×400\# e -400\#. A distribuição granulométrica, tamanho médio e área superficial, de cada fração, foram determinadas. Os testes de flotação foram realizados seguindo uma rigorosa padronização, com a retirada de amostras separadamente a cada minuto. Os produtos foram filtrados, secados e pesados. A avaliação dos resultados foi feita em termos de percentagem em peso da fração flotada. No final foi determinada a curva de variação do potencial zeta em função do pH para apoiar a interpretação dos resultados.

\section{RESULTADOS E DISCUSSÃO}

Os resultados obtidos no granulômetro a laser são mostrados na Tabela 1. Observa-se que as partículas da amostra D (-400 malhas) possuem, em média, área superficial seis vezes maior do que as partículas da amostra A (200×270 malhas). A Figura 1 apresenta a distribuição granulométrica da fração fina (amostra $D$ ).

Tabela 1 - Tamanho médio e área superficial das amostras de quartzo. 


\begin{tabular}{|c|c|c|c|}
\hline AMOSTRA & $\begin{array}{c}\text { GRANULOMETRIA } \\
\text { (malhas) }\end{array}$ & $\begin{array}{c}D_{50} \\
\left(\mu_{\mathrm{m}}\right)\end{array}$ & $\begin{array}{c}\text { ÁREA SUPERFICIAL } \\
\left(\mathrm{m}^{2} / \mathrm{g}\right)\end{array}$ \\
\hline A & $200 \times 270$ & 71 & 0,09 \\
\hline B & $270 \times 325$ & 53 & 0,12 \\
\hline C & $325 \times 400$ & 42 & 0,15 \\
\hline D & -400 & 17 & 0,55 \\
\hline
\end{tabular}

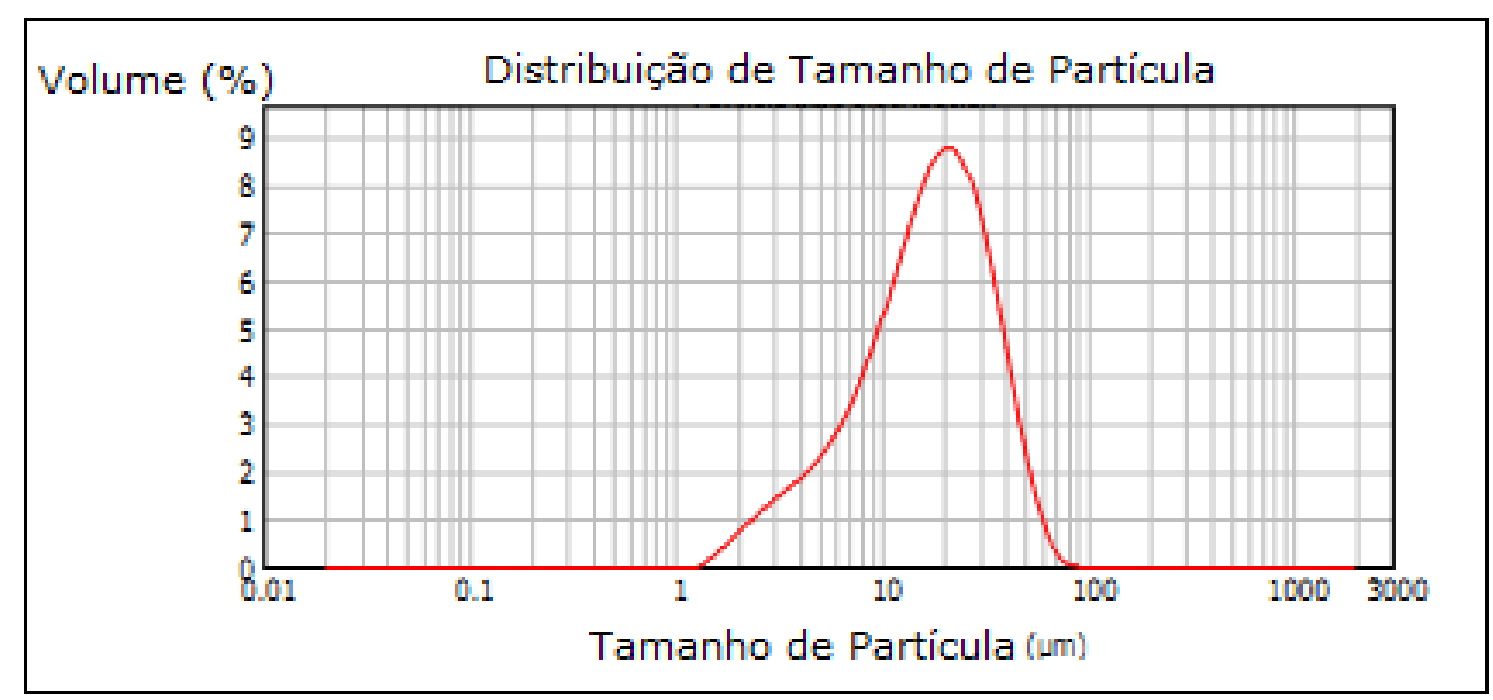

Figura 1 - Distribuição de tamanho de partículas da amostra D com tamanho médio de $17 \mu_{\mathrm{m}}$.

Os resultados apresentados na Figura 2 mostram a recuperação obtida com o quartzo em função do tamanho médio da partícula e do tempo decorrido durante a flotação.

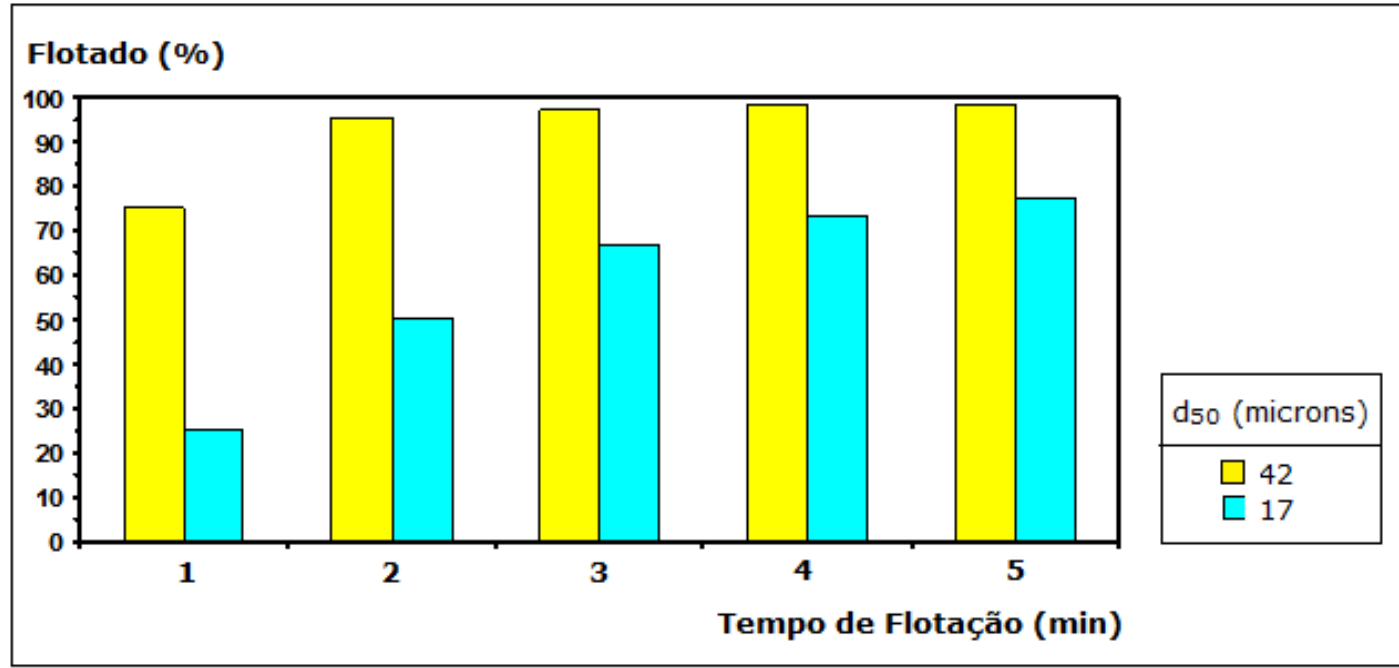

Figura 2 - Influência do tamanho médio da partícula na velocidade de flotação do quartzo com amina $(20 \mathrm{~g} / \mathrm{t})$ em pH natural. 
Os resultados comprovam a maior dificuldade de flotação das partículas mais finas. A amostra $C$, com tamanho médio de $42 \mu_{m}$, flotou praticamente toda com apenas dois minutos de flotação, enquanto a amostra $D$, mais fina, teve uma flotação mais lenta, só conseguindo atingir valores próximos a $75 \%$ após 5 minutos de flotação.

Isso acontece por duas razões principais: (1) menor probabilidade de colisão bolhapartícula e (2) recobrimento superficial insuficiente das partículas mais finas. Considerando-se que a amostra $D$ tem quase quatro vezes a área superficial da amostra $C$, para uma mesma quantidade de moléculas do coletor, a fração da superfície hidrofobizada é menor, diminuindo a probabilidade de adesão. A colisão só resulta em adesão se a bolha de ar tocar uma região hidrofobizada da partícula.

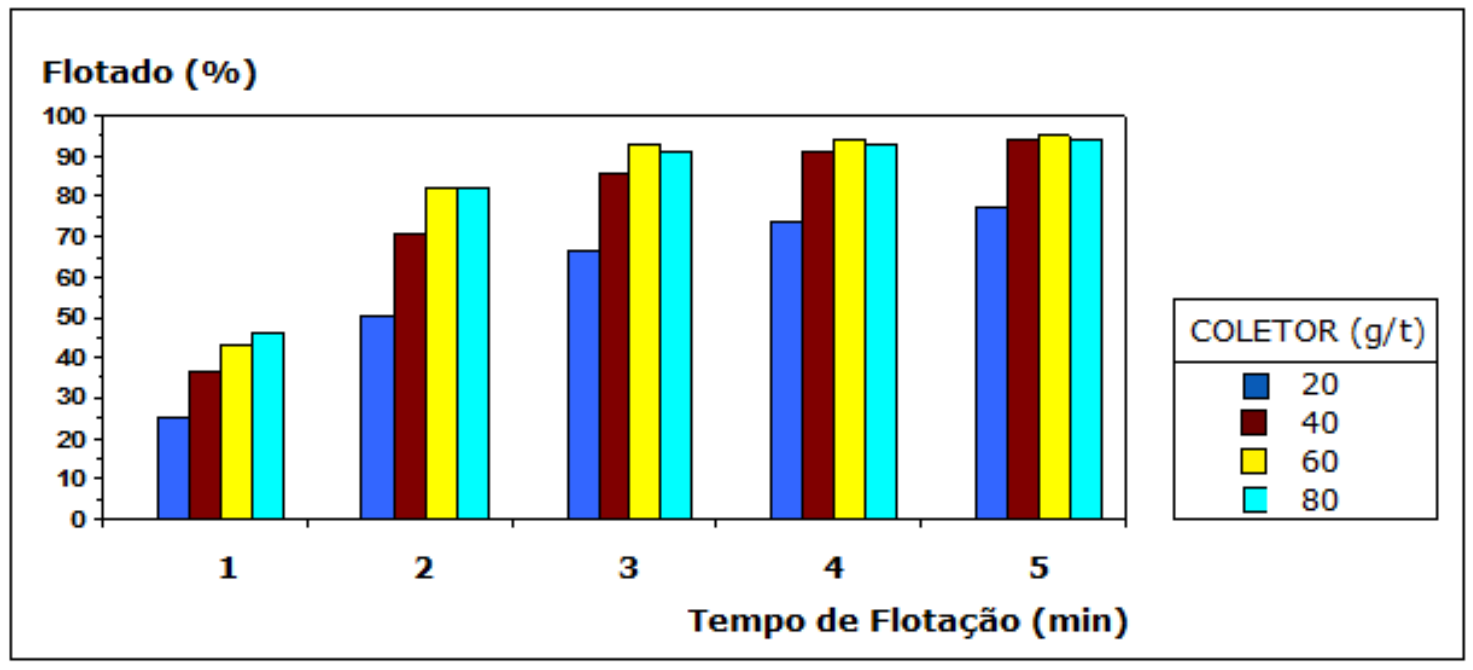

Figura 3 - Influência da concentração do coletor na velocidade de flotação de quartzo $\left(d_{50}=17 \mu_{m}\right)$ com amina em pH natural.

O problema do recobrimento insuficiente da superfície pode ser minimizado por meio de um aumento da concentração do coletor. A Figura 3 apresenta a variação da recuperação do quartzo em função da concentração do coletor e do tempo decorrido durante a flotação.

De fato, os resultados da Figura 3 mostram que a velocidade de flotação aumenta com a concentração do coletor, sugerindo que a disponibilidade de uma maior quantidade de moléculas de amina pode compensar em parte a maior área superficial das partículas finas (Figura 4). 


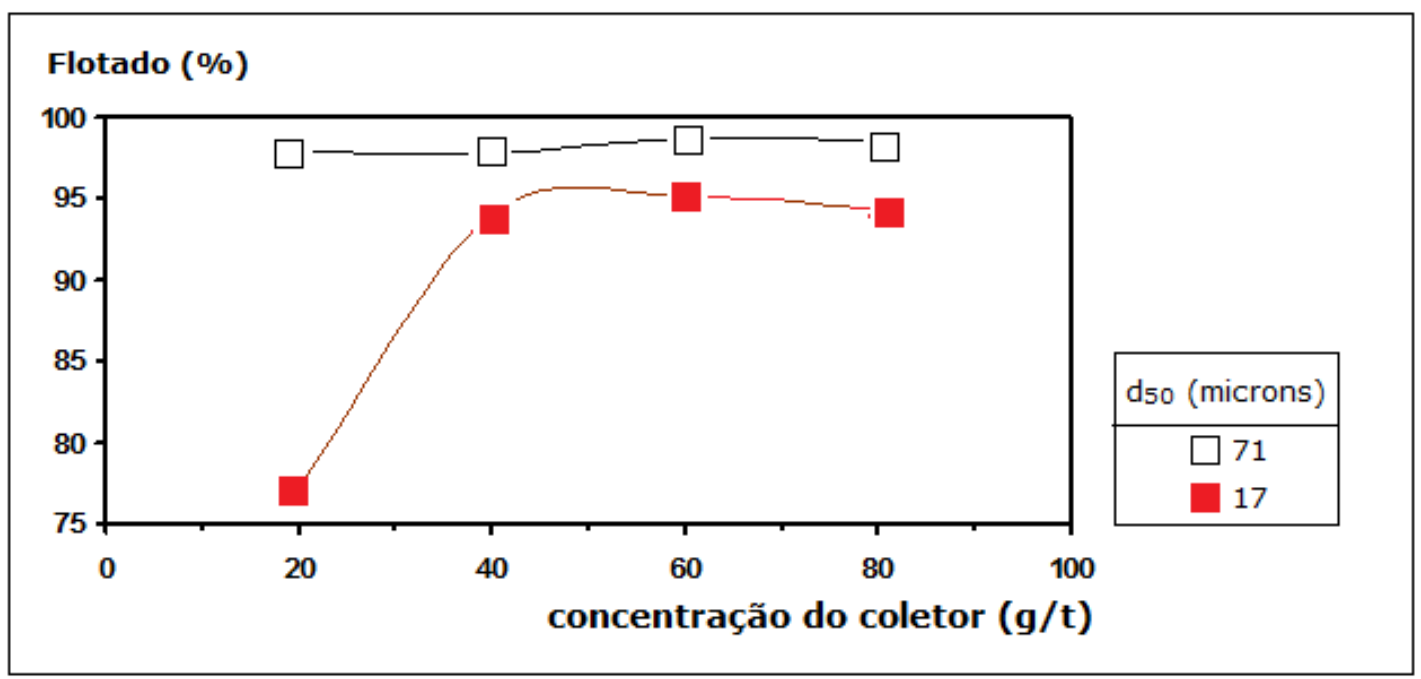

Figura 4 - Recuperação do quartzo em função do tamanho da partícula e da concentração do coletor.

A extensão do recobrimento superficial da partícula pelo coletor, evidentemente, também depende da quantidade de sítios disponíveis para a adsorção. A Figura 5 mostra que a quantidade de sítios negativos na superfície do quartzo aumenta com o pH. Isso significa que o aumento da alcalinidade favorece a adsorção da amina. No entanto, os resultados da Figura 6 mostram que a flotação foi mais lenta em pH 10.

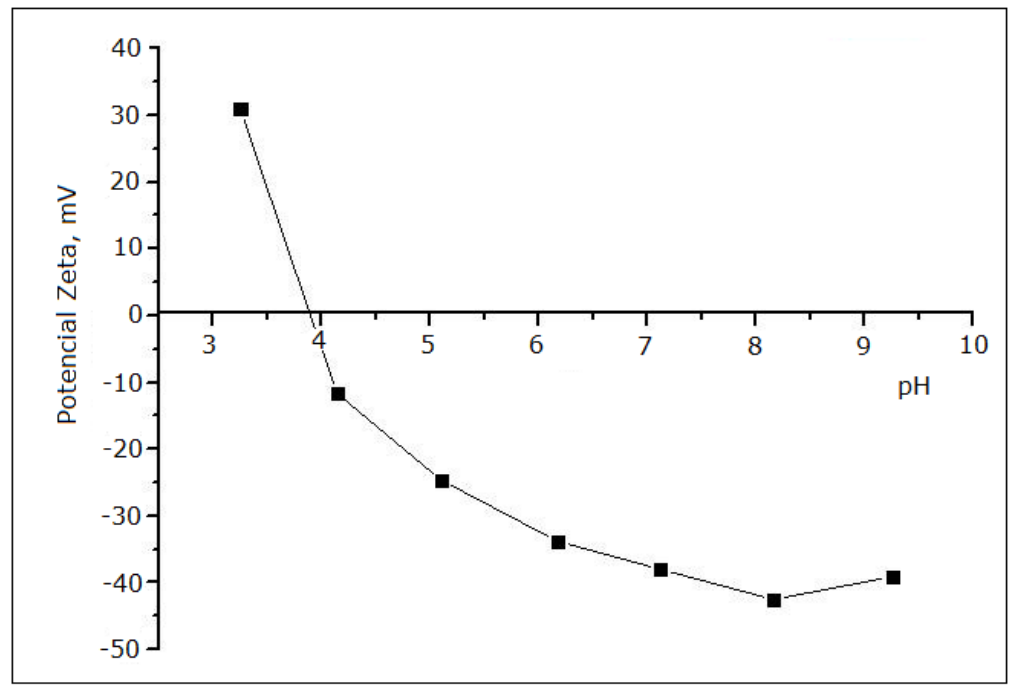

Figura 5 - Variação do potencial zeta do quartzo em função do pH. 


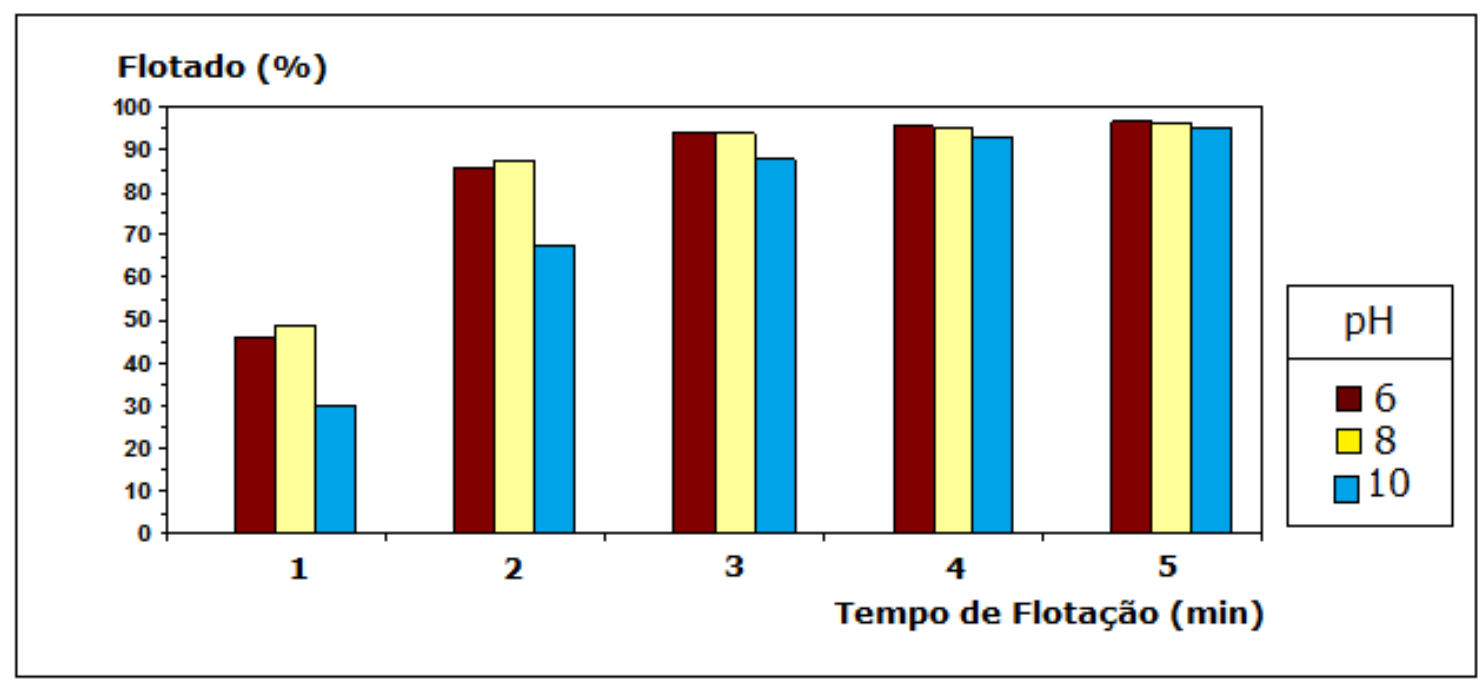

Figura 6 - Influência do pH na recuperação do quartzo com $100 \mathrm{~g} / \mathrm{t}$ de coletor e tamanho médio das partículas de $17 \mu_{\mathrm{m}}$.

Os resultados da Figura 6 podem ser explicados pela diminuição da relação $\mathrm{RNH}_{3}{ }^{+} / \mathrm{RNH}_{2}$ que ocorre em meio bastante alcalino. Apesar da disponibilidade crescente de sítios negativos na superfície do quartzo com a elevação do $\mathrm{pH}$, a quantidade de coletor na forma iônica também diminui resultando em uma menor hidrofobização da superfície.

\section{CONCLUSÕES}

Foi estudada a influência do tamanho da partícula da flotação de quartzo. Observou-se que a amostra com granulometria abaixo de 400 malhas tem uma menor velocidade de flotação.

O problema com a baixa recuperação, inicialmente, obtida com a amostra mais fina $\left(d_{50}=17\right.$ $\mu_{m}$ ) pode ser amenizado com o aumento do tempo de flotação e da concentração do coletor, além de um ajuste do $\mathrm{pH}$ para a região de alcalinidade mais favorável (pH em torno de 8).

\section{AGRADECIMENTO}

Os autores agradecem ao técnico MARCELO FRANCISCO GOMES pelo apoio na etapa experimental do trabalho.

\section{REFERÊNCIAS BIBLIOGRÁFICAS}

ARAUJO, A.C.; VIANA, P.R.M.; PERES, A.E.C. Reagents in iron ores flotation. Minerals Engineering, 18, 219-224, 2005.

BALTAR, C.A.M.; VILLAS BÔAS, R.C. Flotação de minério oxidado de zinco de baixo teor. Série Tecnologia Mineral, $n^{\circ}$ 10; Seção Beneficiamento, nº 8 . MME - DNPM. Brasília, 13 p, 1980.

BALTAR, C.A.M.; CUNHA, A.S.F. DA.; ARAÚJO, J.M.M. de. Estudo das condições para dessorção e reutilização de coletor na flotação de quartzo. In.: XIX Encontro Nacional de Tratamento de Minérios e Metalurgia Extrativa, Anais, v1. Baltar, C.A.M.; Barbosa, J.P.; Oliveira, J.C.S. (editores). Recife, 241-246, 2002. 
BALTAR, C.A.M. Flotação no Tratamento de Minérios, 2ª edição. Editora Universitária da UFPE, Recife, 238 p., 2010.

HUNTER, R,J. Zeta Potential in Colloid Science, Principles and Applications. 3a edição, capítulo 6, Academic Press, 369 p, 1988.

PEARSE, M.J. An overview of the use of chemical reagents in mineral processing. Minerals Engineering, 18, 139-149, 2005. 